\title{
Attention Platforms, the Value of Content, and Public Policy
}

\author{
David S. Evans ${ }^{1,2}$
}

Published online: 24 February 2019

(c) The Author(s) 2019

\begin{abstract}
This paper shows that two related aspects of attention platforms are important for the sound economic analysis of public policy including antitrust: first, attention platforms generate valuable content. Even though people often don't pay for content, we know from revealed preference that content is valuable because people spend a considerable amount of time-which has an opportunity cost—consuming it. Second, demand for advertising and the supply of content are interdependent. A decrease in the demand for advertising reduces the returns to supplying content and therefore the amount of content that is provided. Accounting for the value of content and these positive feedbacks cannot determine optimal interventions; but failing to do so can result in policies that reduce consumer-as well as advertiser-welfare. The paper then considers the implications of these considerations for public policy: particularly privacy regulation and antitrust enforcement. From the standpoint of promoting consumer welfare, the failure to account for the value of content and the ad-content interdependencies increases the chances that authorities do not intervene when they should and do intervene when they should not.
\end{abstract}

Keywords Antitrust · Attention platforms · Industrial organization · Regulation · Multisided platforms $\cdot$ Two-sided markets $\cdot$ Advertising $\cdot$ Media economics

David S. Evans

devans@globaleconomicsgroup.com

1 Global Economics Group, Suite 900, 111 Devonshire St, Boston, MA 02109, USA

2 Bloomsbury, London, UK 


\section{Introduction}

Attention platforms supply content to consumers who spend time on their properties. ${ }^{1}$

During that time, the platforms present ads on behalf of marketers. ${ }^{2}$ Many online attention platforms also collect consumer data, which they use to target ads for marketers. Attention platforms include traditional ad-supported media businesses, such as a radio, television, and print-as well as online businesses, such as search and social. A variety of public policy issues that involve attention platforms-particularly online platforms - have emerged in recent years. These issues include privacy, hate speech, fake news, mergers, and monopolization. ${ }^{3}$

This paper shows that two related aspects of attention platforms are important for the sound economic analysis of these issues: First, attention platforms generate valuable content. Even though people often do not pay for that content, we know from revealed preference that the content is valuable because people spend a considerable amount of their time-which has an opportunity cost-consuming it. Second, the demand for advertising and the supply of content are interdependent. A decrease in the demand for advertising reduces the returns to supplying content. While people may not like ads, they do like content. Accounting for the value of content and these positive feedbacks cannot determine optimal interventions by themselves. However, failure to account for these features of attention platforms can result in poorly designed or unnecessary interventions - as well as not making warranted interventions.

This paper has seven sections including this introduction: Sect. 2 describes the basic economics of attention platforms. It shows that content helps solve a transaction-cost problem and facilitates efficient matching between advertisers and consumers. Section 3 documents the value of content that is supplied by platforms using the time-value approach. It shows that the value of ad-supported content in the U.S. is immense; the use of any plausible measure of the opportunity cost of time reaches that result. Section 4 shows that there are positive feedback effects between the advertiser and user sides of attention platforms, just as there are between the sides of other platforms. In the case of attention platforms, the positive-feedback effect is the result of the interdependence between advertising demand and content supply rather than positive indirect network effects. Section 5 illustrates the importance of these features in conducting cost-benefit calculations of policy interventions that involve privacy. Section 6 then considers the implications of these features for the antitrust analysis of attention platforms. Section 7 offers some concluding remarks.

\footnotetext{
${ }^{1}$ Chairman, Global Economics Group. Executive Director, Jevons Institute for Competition Law and Economics, and Visiting Professor, University College London, London, UK. An earlier version of this paper was the basis for my keynote address at the UniSA \& ACCC Competition Law \& Economics Workshop 2018 in Adelaide, Australia and at the Technology Policy Institute Antitrust and the Platform Economy conference in Washington, D.C. The paper has benefited from comments from participants at those events, in particular Ginger Zhe Jin, and from Lawrence White. Nicholas Giancarlo and Steven Joyce provided exceptional research support.

2 See Evans (2017) for primer on the economics of attention platforms.

3 See Wu (2017) for a discussion of some of these issues for attention platforms.
} 


\section{Basic Economics of Attention Platforms}

An essential feature of all platform enterprises is that they solve a transaction cost problem - a failure of the Coase Theorem - that deters parties from getting together to exchange value. ${ }^{4}$ The platform reduces transaction costs by acting as an intermediary between the two sides and thereby organizing and facilitating trade between different types of customers. This trade increases economic efficiency and surplus for the participants, since, by its nature, trade makes both parties better off.

Attention platforms also solve a transaction cost problem. Marketers would like to deliver messages to consumers in order to increase sales of their products and would pay to do so. Consumers would be willing to receive advertising messages if they were paid enough, ${ }^{5}$ but it is hard for marketers and consumers to get together on their own to do this deal.

Ever since the appearance of ad-supported newspapers in the mid-17th century, attention platforms have adopted similar approaches for solving this transaction cost problem. ${ }^{6}$ These platforms provide content that induces consumers to spend time on the platform. Attention platforms then sell advertisers the ability to reach those consumers by inserting ads on the platform interspersed with the content. Some consumers pay attention to the ads to the benefit of the advertiser. ${ }^{7}$ The content is often designed to attract consumers that advertisers particularly desire, so these platforms serve as matchmakers. ${ }^{8}$ Content, or other related time-intensive services, therefore serves to persuade consumers to spend time on the platform, to provide a place for inserting advertisements, and to match consumers and advertisers. When it comes to

\footnotetext{
${ }^{4}$ See Rochet and Tirole (2006) and Evans and Schmalensee (2016).

${ }^{5}$ Depending on the advertising, and context, consumers may view advertising messages as a source of utility or disutility. To be clear, the disutility of seeing ads refers to the notion that-if people could get the same amount of content- they may prefer to see fewer ads. Of course, people would like to see ads that benefit them so if they could get the same amount of content and precisely the ads they would like to see, they would like that even more. Moreover, as noted by Evans (2017), although consumers may dislike seeing some ads, they collectively benefit from advertising because it promotes competition and entry - as a large number of empirical studies, most based on quasi-natural experiments, have consistently demonstrated.

${ }^{6}$ See Evans (2017) for a discussion of the emergence of attention platforms in the mid $17^{\text {th }}$ century. There are other ways in which businesses could have attempted to solve the transaction-cost problem, including paying consumers a reward for accepting advertising messages; but most advertising is provided by content-centric attention platforms.

${ }^{7}$ Filistrucchi et al. (2014) distinguish between transaction platforms, such as credit card networks, for which there is an observable transaction, and non-transaction platforms such as ad-supported media, for which there is not. This distinction is imprecise given that attention platforms facilitate transactions and that for online platforms there is an observable transaction that results when a consumer clicks on an ad. Attention platforms are different than other platform enterprises mainly because they use content in the ways described above. Since consumers value content separately from ads, attention platforms may face competition from businesses that sell content but not advertising.

${ }^{8}$ Contrary to Wismer and Rasek (2017), ad-supported media platforms engage in matching, crudely in the case of traditional ones such as magazines, but more precisely in the case on online platforms which rely on targeted advertising to match users and advertisers in close-to-real time. See the discussion of
} 
solving the transaction-cost problem, content is king; and time is the currency of the realm.

Der Spiegel, for example, attracts readers with its weekly print magazine that is typically 130-140 pages. The time spent reading an average issue of Der Spiegel is more than $2.5 \mathrm{~h}$, according to a Spiegel response analysis. ${ }^{9}$ Der Spiegel then sells advertisers the ability to present messages to its readers by interspersing ads within and between articles. Spiegel Media, the advertising arm of the Spiegel Brand Family, classifies Der Spiegel readers as "male, educated with high income. 10" Spiegel Media produces editorial content that attracts those readers and then sells advertisers access to them.

Google Search, to take another example, provides search engine results pages (SERPs) to users in response to queries. It sells marketers the ability to present ads on those SERPs through a process in which marketers bid on keywords. Google selects ads that are relevant to the queries and inserts those in the SERPs. In practice, according to Varian (2017), only about a third of SERPs have ads and those that do have four ads on average. The search engine therefore gets people to divert time to search and during some of that time people are matched to advertising.

Although attention platforms could charge consumers for content-and some do-they typically "subsidize" content to capture consumer time. Most online attention platforms provide content for free, as do terrestrial radio stations. Television used to be provided for free over the air in the US so all consumers needed was a television and an antenna. Most consumers now pay for television channels as part of their cable bundle. Although television channels collect revenue from the cable companies based on the number of subscribers, advertising still accounts for a substantial part of their revenues. ${ }^{11}$ Newspapers and magazines are generally sold for less than the cost of printing and distribution; their publishers typically earn most of their revenues from advertising. The subsidized, and often free, provision of content helps resolve the externality between advertisers and consumers.

\section{The Value of Time and Content}

Although consumers can obtain content without advertising through subscription media such as Netflix, attention platforms provide the preponderance of the content that people in developed countries consume during their leisure time. About 80 percent of the time Americans spend consuming content involves ad-supported

\footnotetext{
Footnote 8 (continued)

Der Spiegel and Google Search below. On the use of matchmaking by attention platforms, see Evans and Schmalensee (2016) and Evans (2017).

9 Der Spiegel (2017).

${ }^{10} \mathrm{Id}$.

11 From 2015 to 2017, Time Warner's cable network segment Turner earned $41 \%$ of its revenue through advertisements. See Time Warner Inc. SEC Form 10-K for the fiscal year ended December 31, 2017 at p. 64. Similarly, Viacom's Media Networks segment earned 48 percent of its revenue through advertising from 2016 to 2017. See Viacom Inc. SEC Form 10-K for the fiscal year ended September 30, 2017 at p. 39.
} 
content. ${ }^{12}$ Television, which is generally ad-supported, accounts for about half of leisure time in developed countries and much of the remainder is taken up by adsupported mobile apps and websites. ${ }^{13}$

\subsection{Time-Value Framework for Measuring Consumption and Surplus}

Valuing this content precisely is difficult because so much of it isn't sold at a price. The nature of much content, however, is that people need to invest time to consume it. In fact, as we saw above, that is the whole idea of content: to get people to spend time so that there are opportunities to divert attention to paid advertisements. We can therefore use the economic theory of time allocation, based on Becker (1965), to estimate the value of content. ${ }^{14}$

For traditional goods, such as breakfast cereal, the national income accounts measure the size of the breakfast cereal industry on the basis of consumer spending: the average price per cereal box times the total quantity of cereal boxes consumed. U.S. consumers spent $\$ 185$ billion on breakfast cereals during $2017 .{ }^{15}$ That figure tells us that consumers valued breakfast cereals by at least that amount, relative to what else they could have spent their money on, since the willingness to pay for breakfast cereal exceeds its price for all but the marginal consumer. Since, for demand schedules with similar elasticities, consumer surplus is proportional to the amount spent, spending provides a useful proxy for the welfare that is contributed by different industries. Of course, there are well-known exceptions, but across all products that proportionality is roughly true.

Now consider content: Consumers invest time to consume content. They must value the time that they spend consuming content by at least the opportunity cost of their time; this opportunity cost could involve leisure pursuits such as playing sports, household production such as mowing the grass, or working more such as taking a gig-economy job. Across all consumers, we know that the more time that they invest in consuming content the greater is the total value of that content-in the same sense that the more breakfast cereal that they buy the greater is the total value of breakfast cereal. Consumer surplus is then roughly proportional to that sum, minus the monetary costs of consuming content, with the same qualifications as above. ${ }^{16}$

Figure 1 shows the extension of the usual demand framework to attention platforms. People spend time consuming content until the marginal value of that content equals the marginal opportunity cost of that time-which acts as a price, just as in

\footnotetext{
12 Evans (2017) estimates that 8.7 of the $11.1 \mathrm{~h}(78.4 \%)$ daily that the average American adult spends on content involves ad-supported content.

13 See OECD (2009, Table 2.4).

14 For particular applications it would be important to recognize that the quality of content varies so that consumers place a higher value on a given amount of time spent consuming better content. It would be possible to use discrete choice experiments or similar methods to value content in these circumstances. For a recent application to online content, see Brynjolfsson et al. (2018).

15 Bureau of Economic Analysis (2018a, b).

16 People need to spend money on mobile and fixed broadband subscriptions as well as hardware such as smartphones, computers, and television.
} 
the usual framework. The demand schedule DD represents the value of spending time consuming content. The figure assumes, for illustrative purposes, that consumers have a constant opportunity cost of spending time consuming content of $\mathrm{w}^{*}$. They consume $\mathrm{T}^{*}$ hours of content since at that point the marginal value of content equals the marginal opportunity cost of time. The cost of output equals the amount of time that is devoted to content times its cost or $\mathrm{w}^{*} \times \mathrm{T}^{*}$, which is represented by the darker rectangle; that is analogous to price times quantity (equals sales) for traditional goods. People also obtain consumer surplus, which equals the difference between the value of content and the cost of the time that they invest in consuming it; that is represented by the triangle.

So how big is the consumption of ad-supported content? To calculate the analogy to spending on breakfast cereals we need two numbers: the amount of time that is invested in consuming ad-supported content; and the opportunity cost of that time. The product of those two numbers gives us total "spending" on content that is based on the opportunity cost of time: the rectangle in Fig. 1.

\subsection{Estimates of Time Spent Consuming Content}

Using Nielsen survey data on the time spent consuming various types of media, Evans (2017) estimates that the average American adult in 2016 was exposed to adsupported content for about $8.7 \mathrm{~h}$ a day. That figure includes time when people are multitasking: such as listening to the radio while driving to work, having the television on while making breakfast, and checking their social networks while watching television in the evening. Even that time has some value since consumers who are multitasking on one thing could multitask on another. For instance, a consumer could listen to an audiobook while driving to work instead of listening to ad-supported radio. Evans (2017) used the portion of television viewing time that is spent mainly viewing television to obtain a conservative estimate of the amount of the time that people are devoting to ad-supported media. Using that approach, the average American adult was mainly consuming ad-supported media for $4.9 \mathrm{~h}$ a day (as part of the $8.7 \mathrm{~h}$ during which the adult was exposed to ad-supported media).

Summed across all American adults the amount of time spent mainly consuming ad-supported content is substantially greater than the amount of time they spend on paid work. American adults worked 308 billion hours in $2016 .{ }^{17}$ They allocated 437 billion hours in 2016 during which they mainly consumed ad-supported content (42 percent greater than the amount of work hours) and 779 billion hours during which they were at least partly consuming ad-supported content (153 percent greater than the amount of work hours). The time spent consuming content is worth a lot and so must be the corresponding content.

17 Data on the total adult population of the United States in 2016 taken from U.S. Census Bureau (2016). 


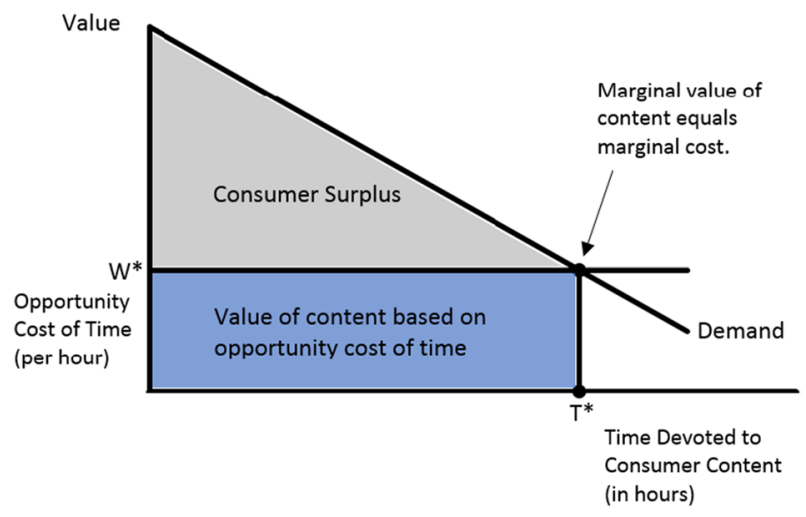

Fig. 1 Consumer "spending" and consumer surplus for attention platforms

\subsection{Estimates of the Value of Content}

To calculate the value of content-in the same sense as consumer spending on breakfast cereal-we need to specify the opportunity cost of time. The key insight from the economic theory of time allocation is that the marginal wage rate provides a reasonable proxy for the value of time. ${ }^{18}$ People have a fixed amount of time to allocate to various activities. If they spend more time engaged in an uncompensated activity, such as going to a ball game, they will have less time to earn money and therefore less income for buying goods and services. The economic theory of time allocation shows that, to maximize their overall well-being, people should allocate time to activities up to the point where the marginal value of time in that activity is equal to the marginal wage they could earn.

Estimating the marginal wage rate is still a challenge. For any given individual, average market wages could be higher or lower than the marginal wage because of the fixity of labor contracts and other institutional reasons. The calculations here use the approach that has been developed by the U.S. Department of Transportation (USDOT) for valuing time in cost-benefit analyses of transportation projects. Based on a review of the empirical literature on the value of time, the most recent U.S. DOT guidance document, issued in 2016, recommended using 50 percent of the before-tax hourly median household income, or $\$ 13.60$ per hour, to value travel time savings for local personal travel. ${ }^{19}$

\footnotetext{
${ }^{18}$ See Ehrenberg and Smith (2012).

19 The calculations it reported were: "The nationwide median annual household income, $\$ 56,516$ in 2015 , is divided by 2080 to yield an income of $\$ 27.20$ per hour." See U.S. Department of Transportation (2016, p. 11).
} 
Multiplying $\$ 13.60$ per hour times the 437 billion hours that were mainly spent consuming ad supported content yields $\$ 5.9$ trillion for 2016 . $^{20}$ That figure seems staggering: U.S. GDP was only $\$ 18.6$ trillion in 2016 . But the magnitude stems from the fact that people spend a substantial portion of the time that they are not working or sleeping mainly consuming ad-supported content. GDP, of course, does not incorporate the value of non-work time.

The point of the preceding calculation is not to provide a precise estimate of the value of content. Given the amount of time spent consuming ad-supported content, however, any plausible estimate of the opportunity cost of time will deliver a substantial value. The value of the time that is spent mainly consuming 437 billion hours of ad-supported content would exceed $\$ 1$ trillion, for example, so long as the value of that time exceeded $\$ 2.29$ an hour. The value would equal $\$ 3.0$ trillion using 25 percent of the before-tax wage ( $\$ 6.80$ an hour which is roughly equal to the aftertax minimum wage in the U.S.) These figures do not include the time during which people were exposed to ad-supported media when they were mainly doing something else. That time was worth something too, since people could have engaged in multitasking that did not involve ad-supported content.

As with spending on breakfast cereal, these figures tell us only that people must have valued that content by at least what they spent on it. Consumer surplus from content measures the value of content over and above the opportunity cost of the time spent consuming it net of out-of-pocket costs. Using the theory of time allocation, Brynjolfsson and Oh (2012), building on the work of Goolsbee and Klenow (2006), estimated the consumer surplus generated by Internet services and television in 2011. Their model assumes that consumers allocate time between paid work, watching television, using the Internet, and a composite good of everything else. ${ }^{21}$

Brynjolfsson and Oh estimate that ad-supported websites generated $\$ 797$ billion, and television generated $\$ 1399$ billion for a total of $\$ 2.2$ trillion of consumer surplus in 2011. Their analysis uses before-tax wages to measure the opportunity cost of time and is therefore double the estimate that is used by USDOT for transportation projects. Therefore, as a rough approximation, we could take consumer surplus as $\$ 1.1$ trillion for ad-supported websites and television as of 2011. Their estimates only partly account for the monetary cost of consuming ad-supported content since they deducted the cost of home broadband but not the cost of television. In 2011

\footnotetext{
${ }^{20}$ Evans (2017) also reports estimates based on: the after-tax minimum wage of $\$ 6.38$ an hour in 2016, which yields $\$ 2.8$ trillion; and the after-tax average wage of $\$ 16.17 \mathrm{~h}$, which yields $\$ 7.1$ trillion. Evans (2017) also used 50 percent of an estimate of the average before-tax wage, which was lower than the estimate reported in the USDOT guidance used here.

21 Brynjolfsson and Oh (2012) measure surplus using the equivalent variation-the amount of additional income the household would need in a world where their internet consumption is zero to have the same utility as the actual world. Note that this measure of consumer surplus accounts for the monetary costs associated with internet consumption (e.g., the monthly cost of a broadband plan); however, it does not deduct the cost of television hardware or cable subscriptions. i.e., they measure the amount of additional income that a household would need in a world with zero internet consumption in order to have the same utility as in the actual world, in which internet consumption has benefits, time costs, and monetary costs. As Brynjolfsson and Oh (2012) show, this net consumer surplus can be identified using variation over time in the share of time spent on the internet, Brynjolfsson and Oh (2012, pp. 6-11).
} 
consumers spent about $\$ 89$ billion on cable subscription ${ }^{22}$ and $\$ 20$ billion for televisions for a total of $\$ 109$ billion. ${ }^{23}$ Deducting $\$ 109$ billion amount from half of the estimated $\$ 1,399$ billion of consumer surplus from television yields a net surplus from television of $\$ 591$ billion. Combined with half of the $\$ 797$ billion in surplus from the Internet yields a total surplus of $\$ 989$ billion. ${ }^{24}$ Based on the figures that are reported in Bhargava et al. (2016), online and television accounted for 75.3 percent of all time spent on media in $2011 .^{25}$ An assumption that the consumer surplus per hour on other media was similar to that for online and television implies total consumer surplus of $\$ 1.31$ trillion. $^{26}$

${ }^{22}$ Smith (2018) reports there were 101.6 million traditional TV subscribers in the U.S. during 2011, that
the average monthly revenue per subscriber during 2016 was $\$ 106.20$, up 44 percent from 2011 , which
implies the average monthly revenue per subscriber was $\$ 73.75$ during 2011 ( $\$ 106.20 / 1.44=\$ 73.75$ ).
Therefore, U.S. TV subscribers spent $\$ 89$ billion on TV subscriptions during 2011 (101.6 million sub-
scribers $\times \$ 73.75 \times 12=\$ 89$ billion).
${ }^{23}$ The NPD Group $(2012)$ reports that U.S. consumer technology hardware sales were $\$ 144$ billion dur-
ing 2011 and that televisions accounted for 13.8 percent of sales, which implies these devices had sales
of $\$ 20$ billion during 2011 ( $\$ 144$ billion $\times 13.8 \%=\$ 20$ billion).
${ }^{24}$ To be even more conservative we could deduct spending on PCs, tablets, and mobile phones. Total
spending on these items was $\$ 55$ billion in 2011 . The NPD Group (2012) reports that U.S. consumer
technology hardware sales were $\$ 144$ billion during 2011 and that PCs, tablets and mobile phones
accounted for 38.5 percent of sales, which implies these devices had sales of $\$ 55$ billion during 2011
( $\$ 144$ billion $\times 38.5 \%=\$ 75$ billion). It is likely that spending on PCs, tablets, and mobile phones would
be substantially greater than zero, even in the absence of the Internet.
25 Bhargava et al. $(2016)$, Fig. 2, which relies on David Pakman, "May I Have Your Attention, Please?" ${ }^{25}$ Bhargava et al. (2016), Fig. 2, which relies on David Pakman, "May I Have Your Attention, Please?" $395 \mathrm{~b} 2 \mathrm{c} 3$ ? curator=MediaREDEF\#.2rwedr27o. The figures in Pakman are not sourced but they are consistent with other estimates from Nielsen data the author has seen.

${ }^{26}$ Syverson (2017) expresses concerns that the time-value approach to estimating consumer surplus may tend to produce overly large estimates of consumer surplus because using wage rates for the marginal value of time may be an overstatement. The consumer surplus estimates reported here use the lower value-of-time estimates that are based on the Department of Transportation estimates to adjust for this possibility. Syverson cites several studies that have considered the monetary cost, but not time cost, of consumer access to broadband. Since there is more variation in wage rates (and thus in the opportunity cost of spending time on the Internet) than in the price of broadband, the time-value approach can identify demand more precisely and can produce valid estimates over a larger range of prices. The monetary approach can only estimate demand at very high prices by extrapolating demand over the range of observed prices using a functional form assumption. Syverson (2017) cites three studies that estimate consumer surplus from broadband access based on monetary demand using data from the last decade: Dutz et al. (2009); Rosston et al. (2010); Nevo et al. (2016). Nevo et al. use an econometrically sophisticated dynamic model to exploit variation in usage rates that come from variation in pricing due to differing probabilities of paying overage rates and is the only one of these three studies to use variation in usage, as opposed to just variation in purchase decisions. This approach enables Nevo et al to take advantage of more variation in prices than the than Dutz et al. (2009) and Rosston et al. (2010). Nevo et al. (2016) estimated that the consumer surplus from a standard broadband plan, which offers 10.8 Mbps, was $\$ 113.50$ per month, which works out to about $\$ 66.21$ per adult, or an annual consumer surplus of $\$ 126$ billion in 2012 (data on the total number of broadband subscriptions in the U.S. is sourced from International Telecommunication Union (2017) and data on broadband use among U.S. adults is sourced from Pew Research Center (2018a)). The estimated consumer surplus was relative to consuming zero GB of Internet content through the single ISP in the data, identified through variation in the choice of plan and usage decisions as the household approaches the threshold for data overcharges. This identification strategy is well-suited for estimating the value of marginal Internet consumption through the studied ISP, relative to the outside options such as not using the Internet, or consuming Internet content at work or through a mobile provider. It is less well-suited for estimating the value relative to switching to another 
These estimates, while rough, demonstrate that the total contribution of ad-supported media to the U.S. economy is considerable. The same situation is true in other developed economies where people typically watch a great deal of television and consume online content on mobile and fixed devices. In analyzing policy interventions that involve attention platforms we would therefore need to account for the impact on the content.

\section{The Interdependence of the Supply of Content and the Demand for Advertising}

Advertisers seek access to consumers. Consumers depend on advertisers to fund the content that they consume. As a result, changes in the attractiveness of the platform to consumers affect advertising revenues, and changes in advertising returns affect the supply of content to consumers. For the purposes of this discussion it is useful to focus on online platforms that have essentially zero marginal costs of distribution and do not charge pecuniary prices. These "free" online platforms-which also collect and use data from consumers-are the focus of recent policy discussions. The basic principles, however, apply more generally.

\subsection{A Simple Model of Buying and Selling Attention for Online Platforms}

A simple model shows the relationship between the consumer and advertiser sides of the platform and captures the essence of that relationship. Attention platforms require certain inputs to provide services to advertisers. They need a consumer to spend time on the platform, so that they can deliver an advertising message. They also want data on the consumer, so as to increase the likelihood that he or she is relevant to the advertiser.

\footnotetext{
Footnote 26 (continued)

ISP or to not using a residential ISP at all, since the data does not include variation in whether or not to use the studied ISP. Since the alternative to using the studied ISP includes other options for accessing the Internet (e.g., at work or through a mobile provider), the consumer surplus estimates may significantly understate the value of internet. Dutz et al. (2009) and Rosston et al. (2010) provide even lower estimates of annual consumer surplus: $\$ 32$ billion in 2008, and $\$ 33$ billion in 2010, respectively. These estimates are implausibly low as an estimate of the value of online services, equaling $\$ 0.58$ per hour for Dutz et al. (2009) and \$0.59 per hour for Rosston et al. (2010). [Rosston et al. (2010) report that the average internet user in their sample spent $15.58 \mathrm{~h}$ online per week. I divide the authors' estimates of yearly surplus per user by the yearly time spent using the internet per user $(15.58 \times 52)]$. These two studies both use surveys to estimate demand, which may be less reliable than market data. Dutz et al. (2009) also report results that use market data but had to rely on an instrument of dubious reliability. Their instrument assumes that over 2005 to 2008 demand shocks are uncorrelated across cities, so that any correlation in broadband prices is due to common cost shocks. Given that this period saw tremendous innovation in online services that are complementary to broadband access, this assumption is unlikely to be satisfied. Brynjolfsson and Oh (2012) implement both a time-usage approach and a monetary demand approach and reach similar findings that the monetary demand approach yields much lower estimates for consumer surplus than the time-value approach and conclude that the time-value approach is more plausible.
} 
Attention platforms have to obtain those inputs from consumers. They do that by giving consumers content that induces them to spend time (which enables the platform to present ads during some of that time) and to provide data (which enables the platform to target ads). The pecuniary price that the attention platform earns from advertisers determines that platform's demand for acquiring the necessary inputs from consumers. A higher price for advertising increases the demand for inputs and therefore how much the platform is willing to invest in content and thus pay in kind for consumer time and data.

Consumers devote more time - and may provide more data and accept more ads-when a platform provides more content, or other services, in exchange for these inputs. Advertisers will pay higher fees for access to a more relevant consumer, which the platform can deliver through curating the relevant audience and by using data to target ads.

Thus, there are significant positive interdependencies between the consumer and advertiser sides in this simple model.

\subsection{The Cost of Content and Feature Creation and Attracting Consumers}

Attention platforms typically provide content that attracts time from many consumers. Content is like other intellectual property in the sense that there is a fixed cost to create it and almost zero marginal cost for making it available to additional users. To attract more consumer time, the platform has to provide more and better content and platform features. Attention platforms typically provide diverse content that attracts more consumers, since some content appeals to some consumers but not others. ${ }^{27}$ They also provide more content and invest in features-such as their websites and mobile apps - that make it more attractive for consumers to spend more time with their content.

Attention platforms have incentives to increase investments in content, and other platform improvements, to secure more attention from consumers, as advertising returns increase. There are many investments that the platform could make to generate content that may involve different mixtures of upfront and ongoing costs. Attention platforms will undertake these investments so long as the returns exceed their minimum investment requirements. As advertising returns increase, attention platforms have incentives to pursue more investments in content, and other features, that attract people's time.

Consumers see the results of these investments in the form of more content, and more engaging content, while advertisers see the results in the form of more attention-and possibly more relevant attention - that they can access.

${ }^{27}$ Bakos and Brynjolfsson (1999, pp. 63-82). 


\subsection{Advertising Returns, Consumers, and Data}

Marketers are interested in the impact of advertising on their sales and profits. That could result from advertising that directly leads to sales or from brand advertising that indirectly encourages sales. Online advertising is typically sold based on the number of impressions (i.e., individuals who are exposed to the advertising message) or on the number of clicks on the ad. Either way, marketers are willing to pay more for advertising that has a higher likelihood of increasing sales and incremental profits. $^{28}$

Advertisers are more likely to make a sale when the ad is targeted at a consumer who has a higher proclivity to buy that advertiser's product. Online attention platforms use data-such as whether the consumer is a parent who has recently purchased diapers - to increase the likelihood of a relevant match between an advertiser and a consumer. The data help identify consumers who are more likely to be interested in buying the advertiser's product. The advertiser realizes a higher return from its ad expenditure when the likelihood of a profitable sale increases after the ad is presented. Consumers are also more likely to value the platform if they are presented with ads that are relevant to them.

Much of the data for efficient matching comes from users. Online platforms typically require some access to data as part of their terms of service, although they may give consumers the ability to decline to make some or all data available.

\subsection{Positive Feedback Effects Between Advertisers and Consumers}

These economic relationships between advertising sales, content creation, attention gathering, and data generation result in positive feedbacks between advertisers and consumers on attention platforms. An increase in advertiser demand increases the returns from generating user attention, which increases the incentives for content creation and platform improvements. More and better content attracts more consumer time to the platform, which enables the platform to sell more ads. Attention platforms use ad revenues to finance content and other features, because that is primarily what generates the attention that results in ad revenues. Conversely, a decline in demand for consuming content, and therefore time spent on the platform, reduces advertising revenue. That in turn reduces the amount of content that the platform offers, which further reduces the amount of consumer time available for advertisers.

These interdependencies between advertisers and consumers are seen most sharply in the decline of newspapers in the U.S. and other developed countries that followed the start of the commercial internet. ${ }^{29}$ Advertising in newspapers declined sharply as advertisers moved spending to online media. Newspapers were forced to reduce the amount of content that they generated, which further reduced readership and advertising revenue. At the same time, the demand for newspaper content

\footnotetext{
28 See Ehrlich and Fisher (1982, pp. 366-388); Duboff (2007); and Tucker (2013, pp. 1025-1054). Advertisers also pay a premium to platforms to reach larger audiences.

29 See van der Wurff (2005); see also The Economist (2006).
} 
declined as readers shifted time to online media. That further reduced the ability of newspapers to finance content.

The total number of newsroom employees in the U.S. newspaper sector declined from 71,600 in 2004 to 39,200 in 2017. ${ }^{30}$ This decline in resources naturally led to a decrease in the amount of content created. Part of the decline in employment came from the newspapers' closing, since it was not possible to support the fixed costs of generating content with the smaller base of advertising revenue and circulation. Newspapers that continued to operate scaled back and produced less content for readers.

A 2008 article in Forbes describes the positive feedback effects well:

Thinner. Lighter. Skinnier. There's a good chance your daily newspaper is a lot easier to lift off your front stoop than it used to be .... [T] he accelerating erosion in advertising revenue has the industry on a shocking starvation diet.... Fewer ads means fewer pages. And those pages are getting smaller too.... [According to a former editor of the Philadelphia Inquirer], "With each of these cutbacks, you give audiences a reason to go somewhere else. ${ }^{31 "}$

Although U.S. newspapers increased prices to readers, their revenues declined as did the amount of content that they produced-as is reflected in the employment figures above.

\subsection{Positive Feedback Effects for Attention and Transaction Platforms}

The positive feedback effects between advertisers and users for attention platforms is similar to so-called transaction platforms-even though the mechanism is different. In the case of transaction platforms there are positive indirect network effects because the demand by members of one group for the transaction service increases with the demand by members of the other group. In the case of attention platforms there is a positive interdependence between advertisers and consumers that results from the use of content to solve the transaction problem between the two sides. In both cases platforms are solving a transaction-cost problem and ultimately facilitating an exchange of value between the participants on both sides.

\section{Economic Analysis of Privacy Policies for Attention Platforms}

Privacy policy illustrates the relevance of the considerations above to sound costbenefit calculations. Recent legislation — such as the General Data Protection Regulation (2016) in the European Union and the California Consumer Privacy Act (2018) - have imposed limitations on the ability to collect data from consumers. Online attention platforms are the main target of these regulations.

\footnotetext{
30 Pew Research Center (2018b).

31 Quoted from Hau (2008).
} 
It is possible that market failures result in attention platforms' securing and using data in ways that consumers would not agree to if better informed. There could also be social benefits from policies that limit the amount of information that companies retain about people. These considerations, by themselves, cannot determine whether a particular privacy policy improves welfare because they do not account for the possible effect of the policy on the consumer surplus that is generated by the platform through the creation of content.

Consider a proposed regulation that limits the amount of data that online platforms can acquire from and about their users: The regulation, for example, might raise the cost to platforms of acquiring the data by requiring various disclosures and explicit grants of permission from users. Or it might restrict the use of data that are collected for the purpose of matching advertisers with consumers. Platforms would provide poorer targeting and measurement to advertisers as a result of collecting less data or being able to use the data less effectively for matching. All else equal, the returns to advertisers from delivering messages would decline, the demand for advertising would shift to the left, and the equilibrium price of advertising would decline.

The platforms would have lower incentives to invest in providing content given that the returns from advertisers, and therefore the returns on their investments in content, would be lower. As a result, the supply of content to consumers would decline. This decline would result for the same reason that newspaper content declined. The returns to making fixed-cost investments in content are lower when the value of the attention that is generated from that content is lower. Consumer surplus from content would fall as the supply of content is restricted.

Whether the benefits of privacy regulation are greater or less than the loss of consumer surplus from less content is an empirical matter. There is certainly no presumption, though, that the net benefits of a decrease in the amount of data available would be positive. Consumers may value privacy and they may dislike some ads. ${ }^{32}$ But they also value content; and, if they are going to be presented ads, they would presumably prefer more relevant ones, which requires data. ${ }^{33}$

\footnotetext{
32 Athey et al. (2017).

${ }^{33}$ A more complete analysis of the effect of privacy regulations would also consider the impact on advertisers and the total surplus that is generated for both sides of the platform. A more complete analysis would also account for the impact of privacy regulation on use and effectiveness of advertising, which tends to benefit consumers generally by facilitating competition and the introduction of new products, as discussed in Evans (2017).
} 


\section{Economic Analysis of Antitrust Interventions}

Modern antirust and merger analysis targets antitrust interventions towards situations in which the subject of the inquiry would likely reduce consumer welfare. ${ }^{34}$ Competition authorities and courts often focus on the impact of the practice at issue on price to assess whether it is likely to reduce consumer surplus. In the case of attention platforms, the effect of business practices that could be subject to an antitrust inquiry on consumer surplus occurs mainly through content. The value of price as a signal is often attenuated through platform "subsidies" and is eliminated with zero pricing, so that price is a poor proxy for evaluating the impact of practices on consumer welfare. ${ }^{35}$

Antitrust analysis can account for the value of content in several ways: For many attention platforms, consumer surplus is likely to be highly correlated with the amount of time that consumers spend on the platform-for the reasons that were discussed above. As shown in Fig. 1 the output of the platform is measured by the time that consumers spend consuming content, and the opportunity cost of time measures the implicit price that they are paying for that content. Consumer surplus is proportional to the value of that time. Discrete choice experiments, which use sophisticated survey techniques to elicit valuations from consumers, provide another way to value content. Brynjolfsson et al. (2018) report results for various online attention platforms. Varian (2017) uses a variant of the time-value approach to measure consumer surplus for search. Search-engines economize on the time that is required to discover information (for example, in comparison to using a physical library). In other cases, it may be possible to use structural econometric models to estimate consumer surplus, such as in Jeziorski (2014).

The antitrust analysis would need to account for the positive feedbacks between the advertising and consumer sides of the attention platform to estimate the effect of a merger or alleged anticompetitive practice on consumer surplus. Failure to account for the value of content, and these interdependencies, could result in false negative or false positive decisions by courts and competition authorities.

To see the possibility of a false negative decision to approve a merger, consider two "free" attention platforms that provide substitutable content: Each platform invests in content and recognizes that consumer time will be diverted to the other platform if its content is poorer than the content of the other platform. In the absence of other significant competitive constraints, after a merger the combined platform would internalize the loss of time to the other platform and reduce its investment in content. The merger would therefore reduce the quantity and quality of content (all else equal), even though both platforms maintain free pricing. The merged platform

\footnotetext{
${ }^{34}$ U.S. antitrust law generally requires evidence that a practice reduces consumer welfare except for per se practices, such as price fixing. The antitrust laws in the European Union and some other jurisdictions are more willing to infer harm to consumers from evidence that an abuse of dominance distorts the competitive process. See, e.g., Elhauge and Geradin (2011).

35 The following discussion considers only the direct impact of practices on consumers as a result of changes in the value of content. A complete analysis would account for the impact on advertisers on the other side of attention platforms.
} 
could also increase data requirements, or reduce privacy protection, for consumers as a result of the decrease in competitive pressure from competing content.

To see the possibility of a false positive decision to allow a merger, consider the same two "free" attention platforms: In this case, however, the merger would reduce the cost of generating content substantially-perhaps because it enables the platforms to amortize the same content across a larger base of viewers. The combined platform would also attract more viewers than either platform separately. Since advertisers are willing to pay more for ads that reach more people, the platform would be able to increase its advertising prices. With higher advertising returnsfrom reduced marginal costs or higher marginal revenues- the platform would have incentives to invest more in content to attract consumer time.

The same basic principles apply to anticompetitive practices in monopolization or abuse of dominance cases. Consider, for example, a case in which a complainant-e.g., a rival platform - argues that an exclusionary practice by a dominant free attention platform depresses its advertising revenue ${ }^{36}$ : The investigating authority determines that the practice does not result in a significant increase in the market price for advertising but mainly diverts advertising from rival platforms and therefore decides to end the investigation. It is possible, however, that by diverting advertising revenue the practice reduces the incentives of competing platforms to invest in content - as a result of the interdependencies described above-and thereby softens competition between the dominant platform and its rivals for consumer attention. Consumer surplus from content therefore declines in the market. In this situation, the competition authority would have reached a false negative decision.

\section{Conclusion}

The role of attention platforms in the economy is understated for two reasons: The first is that much of the value of the output of these platforms isn't accounted for because it doesn't flow through the price system. The exchange of content for time reflects a massive barter economy that is easily neglected. The estimates reported above, while crude, demonstrate that the content generation industry is enormous based on the opportunity cost of time spent consuming content and the magnitude of consumer surplus generated by that content.

The second is that it is easy to discount attention platforms because they sell advertising which people complain about and whose value economists have questioned. ${ }^{37}$ The communication of advertising messages, however, is important for the functioning of competitive markets. ${ }^{38}$ In fact, it is hard to see how competitive markets could function without advertising.

Of course, like any industry, attention platforms could be subject to market failures and anticompetitive behavior. The message of this paper is that sound economic

\footnotetext{
${ }^{36}$ It is also possible that an advertiser might complain about the dominant platform's practices.

37 See Bagwell (2007) for a survey of the literature.

38 See Evans (2017).
} 
analysis should at least account for the value of content, which is considerable, and the positive feedbacks between content supply and advertiser demand. Doing otherwise increases the chances that authorities do not intervene when they should and do intervene when they should not.

Open Access This article is distributed under the terms of the Creative Commons Attribution 4.0 International License (http://creativecommons.org/licenses/by/4.0/), which permits unrestricted use, distribution, and reproduction in any medium, provided you give appropriate credit to the original author(s) and the source, provide a link to the Creative Commons license, and indicate if changes were made.

\section{References}

Athey, S., Catalini, C. \& Tucker, C. (2017). The digital privacy paradox: Small money, small costs, small talk. NBER Working Paper No. 23488.

Bagwell, K. (2007). The economic analysis of advertising. In M. Armstrong \& R. H. Porter (Eds.), Handbook of industrial organization (pp. 1701-1844). Amsterdam: Elsevier.

Bakos, Y., \& Brynjolfsson, E. (1999). Bundling information goods: Pricing, profits and efficiency. Management Science, 45(12), 1612-1630.

Becker, G. (1965). A theory of the allocation of time. Economic Journal, 75(299), 493-517.

Bhargava, H., Evans, D., \& Mani, D. (2016). The move to smart mobile platforms: Implications for antitrust analysis of online markets in developed and developing countries. UC Davis Business Law Journal, 16(2), 158-188.

Brynjolfsson, E., Eggers, F., \& Gannamaneni, A. (2018). Measuring welfare with massive online choice experiments: A brief introduction. AEA Papers and Proceedings, 108, 473-476.

Brynjolfsson, E., \& Oh, J.H. (2012, December), The attention economy: Measuring the value of free digital services on the internet (Paper presented at the 33rd International Conference on Information Systems, Orlando).

Bureau of Economic Analysis. (2018a). National data: Table 2.4.5U. Personal consumption expenditures by type of product. Retrieved July 10, 2018, from https://www.bea.gov/data/consumer-spending/ main.

Bureau of Economic Analysis. (2018b). GDP-by-industry. Retrieved July 10, 2017, from https://www. bea.gov/data/gdp/gdp-industry.

Der Spiegel. (2017). Readership DER SPIEGEL. Retrieved July 10, 2018, from http://spiegel.media/ medien/print/der-spiegel/eng.

Duboff, R. S. (2007). ROI for marketing: Balancing accountability with long-term needs. New York: Association of National Advertisers.

Dutz, M., Orszag, J., \& Willig, R. (2009). The substantial consumer benefits of broadband connectivity for U.S. households. Commissioned by the Internet Innovation Alliance.

Ehrenberg, R., \& Smith, R. (2012). Modern labor economics. Boston: Prentice Hall.

Ehrlich, I., \& Fisher, L. (1982). The derived demand for advertising: A theoretical and empirical investigation. American Economic Review, 72(3), 366-388.

Elhauge, E., \& Geradin, D. (2011). Global competition law. Oxford: Hart Publishing.

European Commission. (2016). General data protection regulation.

Evans, D.S. (2017). The economics of attention markets. Retrieved July 10, 2018 from https://ssrn.com/ abstract=3044858 or http://dx.doi.org/10.2139/ssrn. 3044858 .

Evans, D. S., \& Schmalensee, R. (2016). Matchmakers: The new economics of multisided platforms. Boston: Harvard Business Review Press.

Filistrucchi, L., Geradin, D., van Damme, E., \& Affeldt, P. (2014). Market definition in two-sided markets: Theory and practice. Journal of Competition Law and Economics, 10(2), 293-339.

Goolsbee, A., \& Klenow, P. J. (2006). Valuing consumer products by the time spent using them: An application to the internet. American Economic Review Papers \& Proceedings, 96(2), 108-113.

Hau, L. (2008). The incredible shrinking newspaper. Forbes. Retrieved July 10, 2018, from https://www. forbes.com/2008/04/02/newspapers-advertising-publishing-biz-media-cx_lh_0402sections.html. 
International Telecommunication Union (2017). World telecommunication/ICT indicators database 2017. Retrieved July 10, 2018, from https://www.itu.int/en/ITU-D/Statistics/Pages/publications/wtid.aspx.

Jeziorski, P. (2014). Effects of mergers in two-sided markets: the US radio industry. American Economic Journal: Microeconomics, 6(4), 35-73.

Nevo, A., Turner, J., \& Williams, J. (2016). Usage-based pricing and demand for residential broadband. Econometrica, 84(2), 411-443.

OECD. (2009). Society at a glance 2009: OECD social indicators. Paris: OECD Publishing.

Office of the Attorney General. (2018). California consumer privacy act of 2018

Pew Research Center. (2018a). Internet/broadband fact sheet. Retrieved July 10, 2018, from http://www. pewinternet.org/fact-sheet/internet-broadband/.

Pew Research Center. (2018b). Newspaper fact sheet. Retrieved July 10, 2018, from http://www.journ alism.org/fact-sheet/newspapers/.

Rochet, J., \& Tirole, J. (2006). Two-sided markets: A progress report. RAND Journal of Economics, 37(3), 645-667.

Rosston, G. L., Savage, S. J., \& Waldman, D. (2010). Household demand for broadband internet. Journal of Economics Analysis \& Policy, 10(1), 1-45.

Smith, G. (2018). Who killed the great American cable-tv bundle? Bloomberg. Retrieved January 9, 2019, from https://www.bloomberg.com/news/features/2018-08-08/who-killed-the-great-american-cable -tv-bundle.

Syverson, C. (2017). Challenges to mismeasurement explanations for the US productivity slowdown. Journal of Economic Perspectives, 31(2), 165-186.

The Economist. (2006). Who killed the newspaper? Retrieved July 10, 2018, from https://www.econo mist.com/leaders/2006/08/24/who-killed-the-newspaper.

The NPD Group. (2012). U.S. consumer electronics sales reach $\$ 144$ Billion in 2011. Retrieved January 9, 2019, from https:/www.npd.com/wps/portal/npd/us/news/press-releases/pr_120213/.

Time Warner Inc. SEC Form 10-K for the fiscal year ended December 31, 2017.

Tucker, C. (2013). The implications of improved attribution and measurability for antitrust and privacy in online advertising markets. George Mason Law Review, 20(4), 1025-1054.

U.S. Census Bureau. (2016). Current population survey, annual social and economic supplement. Retrieved July 10, 2018, from https://www.census.gov/cps/data/cpstablecreator.html.

U.S. Department of Transportation. (2016). The value of travel time savings: Departmental guidance for conducting economic evaluations revision 2 (2016 update). Retrieved July 10, 2018, from https ://www.transportation.gov/sites/dot.gov/files/docs/2016\%20Revised $\% 20$ Value $\% 20$ of $\% 20$ Travel $\% 20$ Time\%20Guidance.pdf.

van der Wurff, R. (2005). Impacts of the internet on newspapers in Europe: Conclusions. The International Journal for Communication Studies, 67(1), 107-120.

Varian, H. (2017). The economic value of google. Retrieved July 10, 2018, from http://assets.en.oreil ly.com/1/event/57/The\%20Economic\%20Impact\%20of\%20Google\%20Presentation.pdf.

Viacom Inc. SEC Form 10-K for the fiscal year ended September 30, 2017.

Wismer, S., \& Rasek, A. (2017, June). Market definition in multi-sided markets. (Paper presented at Hearing on Re-thinking the use of traditional antitrust enforcement tools in multi-sided markets, Paris).

Wu, T. (2017). Blind spot: The attention economy and the law. Retrieved July 10, 2018, from https:// papers.ssrn.com/sol3/papers.cfm?abstract_id=2941094.

Publisher's Note Springer Nature remains neutral with regard to jurisdictional claims in published maps and institutional affiliations. 